\title{
ARTIGOORIGINA L
}

\section{ESQUEMAS DISFUNCIONAIS DA PERSONALIDADE E COMPORTAMENTOS DESVIANTES COM JOVENS DELITUOSOS E NÃO DELITUOSOS EM LUANDA-ANGOLA}

DOI: 10.22289/2446-922X.V6N2A13

\author{
Vieira Damba ${ }^{1}$ \\ Nilton Soares Formiga
}

\section{RESUMO}

O presente estudo investigou as crenças disfuncionais, sobre comportamentos anti-sociais dos Jovens em Luanda: um estudo preditivo com sujeitos Delituosos e não Delituosos. Participara da pesquisa 246 jovens, dos quais, 136 estavam em detenção na comarca de Viana e 108 são estudantes do segundo ciclo, matriculados no complexo escolar do Cazenga, e residentes na cidade de Luanda, em Angola. Eles responderam a escala de conductas antissocial e delitiva, questionário de crenças disfuncionais e dados sociodemográficos. Os construtos utilizados foram confiáveis tanto em sua estrutura fatorial quanto em termos da definição teórica dos mesmos. Na análise de regressão, as crenças disfuncionais foram capazes de explicar as condutas desviantes, bem como, as suas respectivas dimensões (conduta antissocial e delitiva). Observou-se um efeito significativo para os fatores Desconfiança/Abuso, Isolamento e Defectividade/Incompetência das crenças disfuncionais, tendo o sexo masculino apresentado escores mais alto, em relação ao sexo feminino, com o 'd' de Cohen maior de $80 \%$. As crenças disfuncionais são interpretações errôneas do processo preceptivo elaborado pelo sujeito; são atitudes de vulnerabilidades a comportamentos antissociais, as quais, apontadas como um fator de risco na juventude. Em determinadas situações, as vivências dos jovens facilitam uma compreensão inadequada da realidade, através de processamentos falhos, isto é, erros de pensamentos que lhes leva a formar conceitos inválidos e desenvolverem crenças disfuncionais, tornando-se vulneráveis e com predisposição a delituosidade.

Palavras-chave: Condutas Antissociais e Delitivas; Crenças Disfuncionales; Jovens Delinquentes e não Delinquentes

\section{DYSFUNCTIONAL PERSONALITY SCHEMES AND DEVIANT BEHAVIORS WITH CRIMINAL AND NON-CRIMINAL YOUTHS IN LUANDA-ANGOLA}

\section{ABSTRACT}

The present study investigated dysfunctional beliefs about anti-social behavior of young people in Luanda: a predictive study with criminal and non-criminal subjects. 246 youths participated in the research, of which 136 were in detention in the district of Viana and 108 are students of the

\footnotetext{
${ }^{1}$ Endereço eletrônico de contato: edivaldovieira23@hotmail.com

Recebido em 13/08/2020. Aprovado pelo conselho editorial para publicação em 17/09/2020.
} 
second cycle, enrolled in the school complex of Cazenga, and residing in the city of Luanda, in Angola. They answered the scale of antisocial and criminal conduct, questionnaire of dysfunctional beliefs and sociodemographic data. The constructs used were reliable both in their factor structure and in terms of their theoretical definition. In the regression analysis, dysfunctional beliefs were able to explain deviant behaviors, as well as their respective dimensions (antisocial and criminal behavior). A significant effect was observed for the factors Mistrust / Abuse, Isolation and Defectivity / Incompetence of dysfunctional beliefs, with the male gender presenting higher scores, in relation to the female gender, with Cohen's ' $d$ ' greater than $80 \%$. Dysfunctional beliefs are erroneous interpretations of the preceptive process elaborated by the subject; they are attitudes of vulnerability to antisocial behavior, which are identified as a risk factor in youth. In certain situations, the experiences of young people facilitate an inadequate understanding of reality, through faulty processing, that is, errors of thought that leads them to form invalid concepts and develop dysfunctional beliefs, becoming vulnerable and predisposed to criminality.

Keywords: Antisocial and Delusional Behaviors; Dysfunctional Beliefs; Delinquent and non Delinquent Juveniles.

\section{ESQUEMAS DE PERSONALIDAD DISFUNCIONALES Y COMPORTAMIENTOS DESVIADOS EN JÓVENES CRIMINALES Y NO CRIMINALES EN LUANDA-ANGOLA}

\section{RESUMEN}

El presente estudio investigó creencias disfuncionales sobre los comportamientos antisociales de los jóvenes en Luanda: un estudio predictivo con sujetos criminales y no criminales. 246 jóvenes participaron en la investigación, de los cuales 136 estaban detenidos en el distrito de Viana y 108 son estudiantes del segundo ciclo, inscritos en el complejo escolar de Cazenga y que residen en la ciudad de Luanda, en Angola. Respondieron la escala de conducta antisocial y criminal, cuestionario de creencias disfuncionales y datos sociodemográficos. Las construcciones utilizadas fueron confiables tanto en su estructura de factores como en términos de su definición teórica. En el análisis de regresión, las creencias disfuncionales fueron capaces de explicar los comportamientos desviados, así como sus respectivas dimensiones (comportamiento antisocial y criminal). Se observó un efecto significativo para los factores Desconfianza / Abuso, Aislamiento y Defectividad / Incompetencia de las creencias disfuncionales, con el género masculino presentando puntuaciones más altas, en relación con el género femenino, con una 'd' de Cohen mayor al $80 \%$. Las creencias disfuncionales son interpretaciones erróneas del proceso preceptivo elaborado por el sujeto; son actitudes de vulnerabilidad al comportamiento antisocial, que se identifican como un factor de riesgo en la juventud. En ciertas situaciones, las experiencias de los jóvenes facilitan una comprensión inadecuada de la realidad, a través de un procesamiento defectuoso, es decir, errores de pensamiento que los llevan a formar conceptos inválidos y desarrollar creencias disfuncionales, volviéndose vulnerables y predispuestos a la criminalidad.

Palabras clave: Conductas Antisociales y Delitivas; Creencias Disfuncionales; Jóvenes Delincuentes y no Delincuentes. 


\section{INTRODUÇÃO}

A delinquência juvenil é um comportamento desviante com graves repercussões nas sociedades modernas; em Angola este fenômeno não está ausente das consequências sociais, educacionais e econômicas do País. O estudo desta problemática visa contribuir para um conhecimento mais profundo sobre esta realidade, por tratar-se de um dos temas mais candentes da atualidade, com implicações ao nível dos comportamentos, atitudes, pensamentos, emoções, crenças e expectativas de soluções e políticas públicas (Formiga \& Gouveia, 2003; Simões, 2007; Redondo,\& Andrés-Pueyo, 2007; Maia, Formiga, Tolentino, Lima, \& Sousa, 2018).

Diante desta perspectiva, importa reforçar que, o comportamento delinquente deve ser analisado em todas suas dimensões e sob as mais diversas perspectivas teóricas, face a relevância do conteúdo destes atos, consubstanciados na observação de que tal fenómeno, não surge de forma estática (Agra \& Matos, 1997; Montagner, 2008; Redondo \& Andrés-Pueyo, 2007; Vayer, 2009; Matos, Simões, \& Gaspar, 2009; Simas, 2012; Pimenta, 2012).

$\mathrm{Na}$ concepção dos autores supracitados, a dinâmica da delituosidade para utilizada para descrever as variáveis ou elementos que formam o entorno interpessoal das vidas cotidianas dos indivíduos, condição essa, que poderá influenciar o comportamento criminal ou delinquente entre os jovens, bem como, causar prejuízo na dimensão social, econômica e humana em determinado contexto cultural. Sendo assim, é possível que a ocorrência de um evento criminal ou delinquente, esteja associado não apenas a essa dinâmica delituosa (isto é, frequência, sentido, quantidade e intensidade de tal ato), mas também, as crenças e o local, situação, motivação e objetivos que podem influenciar o porquê da delinquência juvenil (Costa \& Pimenta, 2006; White, 1943/2005; Formiga \& Diniz, 2011; Formiga, Melo \& Leme, 2013).

Desta maneira, neste artigo, pretende-se apresentar alguns indicadores que contribuam para que atitudes profissionais e de cidadania possam persistir na avaliação e intervenção deste fenómeno na cidade de Luanda, onde a juventude em quase todos bairros urbanos e suburbanos, manifestam comportamentos antissociais com graves repercussões negativas no ponto de vista das comunidades.

No contexto de interesse deste artigo, é preciso destacar a infância e adolescência; estas, são fases tidas como precursor do desenvolvimento de comportamentos inadequados, que podem ser abordados em diferentes pontos de vista, tendo em conta, as normas de convivência de cada sociedade. São definidos como um padrão estável de desrespeito pelos direitos dos outros ou de violações das normas sociais de uma determinada comunidade, podendo englobar diversos atos que podem ocorrer em simultâneo, tais como, a agressividade, o roubo, o vandalismo, a vadiagem, consumo de drogas, atividade sexual desorganizada e a fuga, atos que podem evoluir para comportamentos delituosos na juventude bem como na vida adulta do indivíduo (Pacheco, 2004;

Rev. Psicol Saúde e Debate. Out., 2020:6(2): 184-212. 
Nardi, Filho, \& Aglio, 2016); nestas categorias do fenômeno da delinquência juvenil, muitos são os reflexos destes atos, principalmente, porque estes constituem, na maioria das vezes, a prática do dia-a-dia nas cidades, constituindo um dos principais indicadores para a atividade criminal (Zappe \& Diaz, 2010).

Desta maneira, os comportamentos delinquentes apresentam alguns padrões constantes, tais como (Formiga, 2012; Neves, Duarte, Barbosa, \& Formiga, 2014):

1 - a ocorrência na adolescência e o envolvimento maioritário dos jovens do sexo masculino. Relativamente ao género, os comportamentos antissociais são mais frequentes no sexo masculino, contudo, para as meninas são, maioritariamente, de início tardio e não de início precoce como nos rapazes e há no entanto, uma certa diferença entre os comportamentos praticados pelo sexo masculino e pelo sexo feminino

2 - Em relação à idade, verificou-se, que os comportamentos antissociais têm sido praticados, tanto por rapazes, como por raparigas, até ao final da adolescência e na maioria dos casos, cessam havendo, no entanto, jovens que seguem para uma carreira delinquente. Comportamentos antissociais, como por exemplo, o vandalismo, ocorrem geralmente durante a adolescência, enquanto comportamentos mais graves, como o crime violento e a fraude, tendem a aumentar na idade adulta.

É importante salientar que esses comportamentos não ocorrem esporadicamente e de modo isolado, muitos destes, constituem síndromes (inclusive, aquelas síndromes culturais, as quais, contemplam o individualismo [Formiga, 2014]), que possam representar um desvio de comportamento que pode ser identificado uma trajetória desenvolvimental que é caracterizada primeiro na infância pela inquietude e impulsividade, por distúrbios de oposição ou por dificuldades de aprendizagem; na adolescência, distinguem-se pelo insucesso escolar, consumo de drogas, problemas emocionais, ou consumo de álcool e, na vida adulta, verificou-se sobretudo por problemas de adaptação ao trabalho, dificuldades de relacionamento com os membros da família e com os colegas, alcoolismo e até violência (Born, 2005; Rocha, 2011).

Sendo assim, é possível pressupor que quanto mais precoce for o início dos problemas, maior serão as consequências na trajetória do desenvolvimento e, neste sentido, pior será o prognóstico; em termos de evolução, quanto maior for a diversidade do tipo de problemas desviantes observados, maior será a probabilidade de uma delinquência grave e persistente que se instala no sujeito (Formiga, Melo, \& Leme, 2013). Frente a um fenómeno de características tão complexas é que vem surgir uma quantidade de teorias das mais diversas: das bases da ciência social, passando pela jurídica, às psicológicas (Born, 2005; Rocha, 2011; Paulino \& Almeida, 2014); estas, passam a sustentar as explicações do comportamento antissocial que constatam os aspectos acima referenciados. Irei focar em primeiro lugar, nas teorias clássicas e nas teorias desenvolvimentistas para compreendermos melhor o fenómeno em estudo. 
De acordo com Formiga, Aguiar \& Omar (2008), com a existência de explicações multideterministas a respeito da origem e desenvolvimento das condutas desviantes (por exemplo, estrutura e funcionalidade da família, valores humanos e culturais, desenvolvimento moral, hábitos de lazer etc.), ainda tem sido foco de interesse, o poder explicativo das teorias personalísticas, seja na sua dimensão estrutural, seja funcional.

Independente das perspectivas teórica-avaliativas que se aborde na preditividade dos modelos personalísticos, seja ela ideográfica ou nomotética e até quanto a linha filosófica de pensamento, seja com base no constructo inato ou adquirido, o fato é que, "o estudo da personalidade aponta não apenas em direção da avaliação de uma dinâmica interna na psique do sujeito, mas também, para um caminho dos processos socializantes quanto à formação e à estrutura da personalidade e à sua relação com as condutas humanas" (Formiga, Aguiar, \& Omar, 2008, p. $670)$.

Apesar de não ser uma linha de pesquisa tão nova na Psicologia, ela vem sendo retomada nos últimos quinze anos, acrescentando informações, predições e compreensão a respeito dos motivos que levam ao comportamento humano que conduzem à violência (antissociais e delitivos, comportamento agressivo, uso de drogas, etc.) (Vasconcelos, Gouveia, Pimentel, \& Pessoa, 2008).

Desta maneira, "o estudo da personalidade, baseado na concepção dos traços vem revelando um poder explicativo bastante convincente, pois, a concepção da personalidade a partir dos traços não diz respeito às questões patológicas, mas à díade genética/meio ambiente, que implica características individuais consistentes do comportamento exibido pelo indivíduo em diversas situações, características essas que são normalmente concebidas como disposições" (Formiga, Omar, \& Aguiar, 2010, p.101). Na teoria dos traços, são geradas taxonomias que permitem ao sujeito se expressar através das condutas, formas específicas para si e para os outros quando em interação social, a qual, na maioria das vezes atenderia à desejabilidade social, tendo que desenvolver uma autoimagem codependente dos papéis sociais representados individualmente, condição que permite gerar e gerir no sujeito, determinadas crenças a seu respeito.

O tema personalidade tem sido objeto de estudo de muitos autores, que o definiram de modos diversos. Frente às diferentes definições e concepções que se tem acerca do tema, optouse pela concepção referente à abordagem cognitiva, de acordo com a qual a personalidade é considerada como sendo formada por valores centrais, desenvolvidos bem cedo na vida dos indivíduos e resultantes de fatores presentes em seu ambiente (Freeman \& Datilio, 1998; Friedberg \& McLure, 2004).

Segundo Beck e Freeman (1993) e Beck, Butler, Brown, Dahlsgaard, Newman \& Beck (2001) estes valores são estruturas cognitivas organizadas categóricas e hierarquicamente, conhecidas como esquemas. De forma geral, o esquema é uma estrutura que filtra, codifica e avalia os estímulos aos quais se submete o organismo (Beck, 2013). O indivíduo consegue, assim, orientar- 
se em relação ao tempo e espaço, categorizar e interpretar experiências de maneira significativa, com base em seus esquemas (Beck, 2013; Young, Klosko, \& Weishaar, 2008)

Os esquemas são estruturas cognitivas organizadas categóricas e hierarquicamente. Eles caracterizam um sistema de processamento de informações que modula a recepção e a resposta aos estímulos externos e internos. Por meio deles, os indivíduos elaboram, selecionam e codificam ativamente as informações, interpretando os eventos que acontecem a si e aos outros. Os esquemas precedem, selecionam e acionam estratégias comportamentais relevantes e moldam profundamente o funcionamento emocional e comportamental dos indivíduos estes valores são estruturas cognitivas organizadas categórica e hierarquicamente, conhecidas como esquemas (Beck \& Freeman, 1993; Freeman \& Dattilio, 1998; Beck, Butler, Brown, Dahlsgaard, Newman, \& Beck, 2001; Friedberg \& McClure, 2004; Beck, Freeman, \& Davis, 2005).

Os esquemas auxiliam a entender e a organizar o mundo e, considerando o grande número de estímulos simultâneos apresentados a todo instante aos indivíduos, representam formas econômicas de processamento de informações. Embora afetem as reações emocionais e comportamentais dos indivíduos, os esquemas não necessariamente causam dificuldades emocionais ou comportamentais (Greenberg \& Beck, 1989; Padesky, 1994).

Desta forma, contribuem para a manutenção do esquema as distorções cognitivas (percepções distorcidas dos eventos) e os padrões de comportamento auto derrotistas (maneiras padronizadas de se relacionar com os outros que perpetuam os esquemas). Já o processo de evitação do esquema se dá em decorrência da intensa carga afetiva que é ativada quando um esquema é acionado. São comuns evitações cognitivas (de pensamentos ou imagens mentais), evitações afetivas (bloqueios dos sentimentos) e comportamentais (de situações ou circunstâncias cotidianas), as quais poderiam desencadear interpretações dolorosas (Young 2003; Young et al., 2008). Por fim, na super compensação, os indivíduos assumem estilos cognitivos ou comportamentais que parecem ser o oposto de seus esquemas iniciais. Este processo pode ser funcional, a menos que não ultrapasse os limites de uma vida saudável (Young, 2003; Young, Klosko, \& Weishaar., 2008)

Neste contexto, as crenças disfuncionais são concebidas também, como interpretações errôneas do processo preceptivo elaborado pelo sujeito; são consideradas atitudes de vulnerabilidades a comportamentos antissociais, as quais, apontadas como um fator de risco na juventude (Rocha, 2011). Em determinadas situações, suas vivências facilitam uma compreensão inadequada da realidade, através de processamentos falhos, isto é, erros de pensamentos. Estes, conduzem para a formação de conceitos inválidos e desenvolvimento de crenças, chamadas disfuncionais, tornando-se vulneráveis e com predisposição a delituosidade (Beck, 2013; Young, 2003; Rocha, 2011). 
Concebendo as crenças disfuncionais como vulnerabilidades de comportamentos antissociais, assumindo como um fator de risco na juventude, busca-se, numa amostra de jovens (com e sem história de delinquência) da cidade de Luanda, o quanto as crenças disfuncionais se relacionam com os comportamentos antissociais, bem como, a variação média das respostas em cada grupo juvenil em tais crenças é capaz de influenciar na variação da intensidade das condutas antissociais e delitivas.

\section{MATERIAIS E MÉTODOS}

\section{Amostra}

Trata-se de um estudo descritivo, exploratório e correlacional, de abordagem quantitativa envolvendo jovens com e sem história de delinquência na cidade de Viana - Luanda. A pesquisa foi desenvolvida por meio de uma amostra aleatória simples, do tipo intencional, abordando o método bola de neve, isto é, os sujeitos dos referidos contextos destinados a pesquisa, eram visitados e pedia-Ihes que respondessem ao questionário apresentado.

Neste estudo a amostra foi constituído por, 246 jovens, dos quais, 138 estavam em detenção na comarca de Viana e 108, eram estudantes do segundo ciclo, matriculados no complexo escolar do Cazenga, e residentes na cidade de Luanda, em Angola. Para avaliar a qualidade e significância da amostra para a realização dos cálculos desejados, utilizou-se o pacote estatístico G Power 3.1; este tipo de software destina-se ao cálculo do poder estatístico (isto é, o teste de hipótese) amostral e que tem como base de avaliação, não apenas o ' $n$ ' necessário para a pesquisa, mas, também, o tipo de cálculo a ser realizado (Faul, Erdfelder, Lang, \& Buchner, 2007).

Para a coleta de dados deste estudo, considerando uma probabilidade de $95 \%(p<0,05)$, magnitude do efeito amostral $(r \geq 0,30)$ e um padrão de poder hipotético $(\pi \geq 0,80)$ para amostra total e a especificidade amostral, observou-se os seguintes critérios: amostra total $(\mathrm{t} \geq 1,98 ; \pi \geq$ 0,$97 ; p<0,05$ ), amostra 1 (amostra dos jovens delinquentes) $[t \geq 1,98 ; \pi \geq 0,93 ; p<0,05]$ e amostra 2 (amostra de não delinquentes) [ $t \geq 1,93 ; \pi \geq 0,95 ; p<0,05]$. Tais indicadores estatísticos, não apenas garantiram que a amostra era suficiente, mas, também, que com ela seria possível avaliar as hipóteses, considerando os cálculos descritivos, inferenciais e preditivos.

No que se refere ao critério de exclusão, considerou-se que, os sujeitos que não faziam parte da amostra seriam os jovens com idade abaixo de18 anos e os prisioneiros detidos ou condenados com idade maior de 25 anos, bem como, aquele sujeito que negava-se participar da pesquisa.

Ao considerar assim, a nossa preocupação constituiu apenas em trabalhar com os jovens do sexo masculino e feminino com idades compreendidas entre os 18 a 25 anos de idade, presos 
na comarca de Viana em Luanda e que foram selecionados, com base na pesquisa por intencionalidade, tendo em conta a complexidade do processo que envolve estes detidos não nos foi possível, caracterizar os sujeitos com base a tipicidade do crime, porque muitos destes estavam sob segredo de justiça e em prisão preventiva.

\section{Instrumentos}

Neste trabalho, tendo em conta a existência de duas variáveis distintas (Crenças disfuncionais sobre Comportamentos desviantes [este, distribuído em duas dimensões - antissocial e delitivos] e com vistas em atingir resultados que satisfaçam a respectiva pesquisa, viu-se a necessidade de proceder a utilização de dois instrumentos:

- Questionário de Escala de Crenças Disfuncionais: trata-se de uma escala adaptada e validada para o contexto brasileiro por Cazassa (2007; Cazassa \& Oliveira, 2008) e é composta por cinquenta e sete questões, nas quais, o respondente deverá indicar as suas respostas numa escala do tipo Likert de seis pontos devendo marcar o número no item que mais o descreve (isto é, 1 - não me descreve de modo algum, 2 - Acontece raras vezes e pouco descreve o meu modo de ser, 3 = Acontece algumas vezes, mas ainda não descreve o meu modo de ser, 4 = Descreve o meu modo de ser, 5 = Descreve muito o meu modo de ser e 6 = Me descreve perfeitamente).

Este instrumento avalia os quinze esquemas de personalidade, referentes as crenças disfuncionais e que se encontram distribuindo em cinco grandes domínios, a saber: Desconexão e Rejeição, Autonomia e Desempenho Prejudicados, Limites Prejudicados, Orientação para o Outro, Super vigilância e Inibição (cf. Young, 2003). No estudo de Cazassa (2007), em relação ao grau de consistência interna da referida escala, para a população brasileira, observaram-se que os alfas de Cronbach foram $>0,70$, isto é, obteve 0,95 , condição essa, que indica um excelente grau de consistência interna

Com base nos resultados do estudo de Cazassa (2007), Rocha, Formiga e Lopes (2016) desenvolveram um estudo semelhante, porém, administrado em presidiários com diferentes tipos de crimes e tempo de penas, na cidade de Uberlândia, no Estado de Minas Gerais, Brasil. De acordo com os autores, o alfa esteve dentro do padrão observado no estudo de Cazassa (2007), isto é, superior 0,95 , revelando com isso, indicadores psicométricos confiáveis, denotando que tal escala continua apresentar critérios de adaptação e adequabilidade para a população de presidiários.

No que se refere ao processo de avaliação das crenças, ela é medida, a partir do somatório de todos os itens, formando um único fator; neste, tanto poderá ser avaliar a crença disfuncional total com base na superioridade das médias, com isso, quanto maior a média, maior a disfuncionalidade. Bem como, realizar uma avaliação quanto ao nível do esquema (baixo, 
moderado, alto), o qual, é organizado com base nos percentuais dos quartis (25\%-50\% - $75 \%$ $100 \%)$.

Também, poderá ser avaliado, tanto através dos esquemas (os quais, são quinze - Privação Emocional, Abandono, Desconfiança/ Abuso, Isolamento Social, Defectividade/ Vergonha, Fracasso, Dependência/ Incompetência, Vulnerabilidade a Dores e Doenças, Emaranhamento; Subjugação, Auto sacrifício, Inibição Emocional, Padrões Inflexíveis, Merecimento, Autocontrole/ Autodisciplina Insuficientes), quanto por meio dos cinco domínios originado dos quinze esquemas (os quais, são - Desconexão e Rejeição, Autonomia e Desempenho Prejudicados, Limites Prejudicados, Orientação para o Outro, Supervigilância e Inibição). Todos eles, podem seguir o mesmo padrão psicométrico para avaliação do constructo realizado para as crenças disfuncionais gerais.

Por falta de instrumentos sobre a avaliação das crenças disfuncionais na realidade angolana, sobretudo para mensurar tais variáveis aos sujeitos, com e sem história de delinquência, teve-se como recurso metodológico e empírico para avaliação de tal constructo, a aplicação da escala de crenças disfuncionais, o qual, de forma geral, é um questionário com diversos itens capaz de avaliar o constructo em questão, sendo usado por vários autores, mostrando resultados muito consistentes (Cazassa, 2007; Rocha, Formiga, \& Lopes, 2016).

- Escala de condutas antissociais e delitivas - Para avaliar os comportamentos desviantes, foi aplicado a Escala de Condutas Antissociais e Delitivas (ECAD); esta escala foi, inicialmente, proposta por Seisdedos (1988) para o contexto espanhol e validada por Formiga e Gouveia (2003) para o contexto Brasileiro. Trata-se de uma medida capaz de avaliar a condutas desviantes em jovens, sendo composta por 40 itens, distribuindo em dois fatores (20 itens compõem conduta antissocial e 20, a conduta delitiva); a primeira, refere-se aos comportamentos que desafiam a ordem social (e.g., jogar lixo no chão mesmo quando há perto um cesto de lixo; tocar a campainha na casa de alguém e sair correndo), enquanto a segunda, diz respeito a comportamentos considerados como estando à margem da lei, caracterizando uma infração ou uma conduta faltosa e prejudicial a alguém ou mesmo à sociedade como um todo (e.g., roubar objetos dos carros; conseguir dinheiro ameaçando pessoas mais fracas) (cf. Maia, Formiga, Tolentino, Lima, \& Sousa, 2018).

Esta escala compreende-se uma medida comportamental em relação ás condutas antissociais e Delitivas e tem sido usada em vários países (Portugal, Argentina, México) (cf. Formiga \& Gouveia, 2003; Vera, Bautista, Ramírez, \& Yáñez, 2012; Formiga, Duarte, Neves, Machado, \& Machado, 2015; Formiga, Souza, Estevam, \& Omar, 2016) como uma medida comportamental do desvio juvenil, evidenciando resultados muito consistentes. Num último estudo no Brasil, Maia, Formiga, Tolentino, Lima e Sousa (2018), os quais, avaliaram jovens de 12 a 19 anos, observaram 
que os alfas estiveram tanto acima de 0,70, revelaram correlações intraclasse também, acima do esperado. Tal condição permite afirmar que a medida ECAD é consistente e fidedigna.

No que se refere a condição de avaliação as respostas, para cada item, os respondentes devem indicar, numa escala de Likert de 0 a $9(0=$ Nunca e $9=$ Sempre), a frequência do comportamento assinalado é ou foi realizado no decorrer de sua vida juvenil. Tendo as respostas, esta, poderá ser avaliada seja através das médias, nesta condição, efetua-se o somatório de todos os itens, separadamente, da escala total (estabelecida como, CAD) ou do somatório dos itens que compõem as duas dimensões (especificamente, a conduta antissocial e a delitiva); com isso, realização o cálculo da média (bem como, desvio padrão) e obtém-se os resultados, os quais, podem ser analisados da seguinte forma: quanto maior a média para estas dimensões, maior é a conduta desviante, bem como, na especificidade das condutas, maior a média na conduta antissocial e delitiva, respectivamente, maior será essa conduta nos jovens respondente da pesquisa.

Outra forma de avaliar a escala no grupo de respondentes, é através do nível de condutas apresentadas por eles; esta maneira de avaliação segue a distribuição dos quartais (25\% - 50\% $75 \%$ - 100\%), entalecendo os critérios do nível da conduta (por exemplo, Baixo, Moderado e Alto). Assim, considerado, estabelece as condições quanto a potencialidade do risco, caso apresente maior percentual no nível moderado ou um grande risco a conduta (antissocial e/ou delitiva), se apresentar um percentual acima de $75 \%$ no nível alto.

Reconhecendo a escassez de instrumentos de medida da delinquência juvenil adaptados à população Angolana e considerando que a ECAD reúne características favoráveis a uma análise integrada e não restritiva do fenómeno em apreço, acredita-se que a referida escala, seja viável para esta tese; sendo assim, utilizou-se a Escala de Condutas Antissociais e Delitivas (ECAD), uma medida comportamental composta por 40 itens, distribuídos em dois fatores: (a) condutas antissociais e (b) condutas delitivas.

Além desses instrumentos, foi acompanhado um questionário sóciodemográfico, com o objetivo de fazer uma breve caracterização dos participantes do estudo no que respeita ao sexo, idade e nível de escolaridade.

\section{Administração do Instrumento da Pesquisa e Análise de Dados}

Antes da aplicação dos instrumentos pretendidos, primeiro solicitamos uma autorização dirigida aos serviços penitenciários do Ministério do Interior da República de Angla, onde manifestamos os objetivos da referida pesquisa e passados cerca de três meses, só assim que foi possível obter a devida autorização. Este procedimento é o mesmo também que foi aplicado no Complexo escolar do Cazenga, onde solicitamos uma autorização ao Sr., Diretor do referido 
complexo escolar, onde esclarecemos os objetivos da pesquisa, na intenção de tralhar com os estudantes daquele estabelecimento de ensino escolar e que de imediato foi possível a sua autorização.

Desta forma, já em presença destas autorizações, os instrumentos foram encaminhados aos respondentes, pessoalmente, quando visitado os locais em que estes se encontravam (para aqueles que se encontravam detidos na Comarca de Viana em Luanda, quanto aqueles os não detidos que se encontram matriculados no complexo escolar do Caenga. A estes dois grupos, foi solicitada a participação no estudo, aos quais, era informado que o objetivo do estudo seria o de avaliar a percepção das pessoas relativamente ao seu comportamento social durante o seu desenvolvimento juvenil.

Aqueles que se mostraram interessados em participar, pedia-lhe o seu consentimento para inserir-se no estudo e fazer parte da amostra do mesmo; foram esclarecidas informações no que se refere as suas respostas, as quais, são pessoais e sem interferência do administrador da pesquisa, assim: ao responder o instrumento, não haveria respostas certas ou erradas e estas, seriam tratadas de acordo com o que o sujeito pensou ao ler as questões apresentadas e indicou a sua resposta no instrumento apresentado.

Também, foi assegurado o anonimato das respostas, bem como, que as questões respondidas seriam tratadas em seu conjunto de resposta e não na particularidade da resposta de cada sujeito. Apesar de se encontrar as instruções necessárias para que o questionário possa ser respondido, o pesquisador (com experiência prévia na pesquisa) esteve presente durante toda a aplicação do instrumento, caso o respondente necessitasse de esclarecimento sobre as dúvidas que surgissem; um tempo médio de 50 minutos era suficiente para que a atividade pudesse ser concluída.

No que se refere a análise dos dados, utilizou-se o pacote estatístico SPSSWIN, em sua versão 24.0, para tabular os dados e realizar as análises estatísticas descritivas (média e desvio padrão, mediana), correlação de Pearson, teste de $t$ de Student e alfa de Crombach, ANOVA Oneway.

Este cálculos, respectivamente, para descrição da amostra e das respostas dos sujeitos nas escalas a eles apresentadas; os demais cálculos destinavam-se para avaliação de causa e efeito tanto entre itens e constructo, quanto entre os próprios construtos, bem como, para diferenciar os níveis mais alto e mais baixo apresentado pelos sujeitos em cada item do instrumento e por fim, o alfa, destinou-se à avaliação da consistência dos instrumentos, devido a especificidade do contexto amostral da pesquisa.

Para verificar a proposta do modelo teórico, o qual, já previamente hipotetizado tanto em seu conceito e fatorialização quanto em sua qualidade psicométrica (Rocha, Formiga, \& Lopes, 2016; Maia, Formiga, Tolentino, Lima e Sousa, 2018), realizou-se no programa AMOS Grafics 22.0 a 
verificação dos indicadores estatísticos através do cálculo de Modelagem de Equações Estruturais (MEE), para o qual, considerou-se tanto a adequação de ajuste subjetiva dos índices de modificação quanto das orientações empíricas indicadas pelos autores supracitados.

O fato em ter que trabalhar com esse programa estatístico, se deve ao motivo que ele tem a função de apresentar, de forma mais robusta, indicadores psicométricos que vise uma melhor construção da adaptação e acurácia da escala desenvolvida, bem como, permita desenhar um modelo teórico pretendido no estudo. Sendo um tipo de análise estatística mais criteriosa e rigorosa, testou-se o modelo teórico que se pretendia, considerando alguns índices que permitem avaliar a qualidade de ajuste do modelo proposto (Hair Jr et al., 2005; Van De Vijver \& Leung, 1997):

$O \mathrm{X}^{2}$ (qui-quadrado) testa a probabilidade do modelo teórico se ajustar aos dados: quanto maior o valor do $X^{2}$ pior o ajustamento. Entretanto, ele tem sido pouco empregado na literatura, sendo mais comum considerar sua razão em relação aos graus de liberdade ( $X^{2} / g$. ..). Neste caso, valores até 3 indicam um ajustamento adequado; O Goodness-of-Fit Index (GFI) e o Adjusted Goodness-of-Fit Index (AGFI) são análogos ao $\mathrm{R}^{2}$ na regressão múltipla e, portanto, indicam a proporção de variância - covariância nos dados explicados pelo modelo. Os valores desses indicadores variam de 0 a 1, sendo que os valores na casa dos 0,80 e 0,90 , ou superiores, indicam um ajustamento satisfatório; A Root-Mean-Square Error of Approximation (RMSEA), com seu intervalo de confiança de 90\% (IC90\%), é considerado um indicador de "bondade" de ajuste, isto é, valores altos indicam um modelo não ajustado. Assume-se como ideal que o RMSEA se situe entre 0,05 e 0,08, aceitando-se valores até 0,10; O Comparative Fit Index (CFI) - compara de forma geral o modelo estimado ao modelo nulo, considerando valores mais próximos de um como indicadores de ajustamento satisfatório; Root-Mean-Square Error of Approximation (RMSEA), com seu intervalo de confiança de 90\% (IC90\%), é considerado um indicador de adequação de ajuste, isto é, valores altos indicam um modelo não ajustado. Assume-se como ideal que o RMSEA se situe entre 0,05 e 0,08 , aceitando-se valores de até 0,10 .

\section{RESULTADOS}

Nesta etapa inicial optou-se em apresentar resultados relacionados a discriminação e representatividade de conteúdo dos itens e os indicadores de consistência interna das escalas administradas aos respondentes. Na segunda etapa foi realizada uma análise e a verificação da estrutura fatorial das escalas, com base nas direções avaliativas dos autores que a desenvolveram. Para finalizar, na terceira etapa, foi apresentado os resultados das correlações e as análises de variâncias entre as variáveis em questão.

Rev. Psicol Saúde e Debate. Out., 2020:6(2): 184-212. 
A amostra do estudo foi composta por dois grupos distintos; uma com 138 jovens de ambos os sexos, sendo 57 do sexo masculino e 81 do sexo feminino, em detenção no município de Viana em Angola, tendo sido a maioria da amostra de sexo feminino (59\%), com idade compreendida entre os 18 a 35 anos $(M=26.5$, d.p. = 7,80). O restante da amostra para completar o ' $N$ ' total, destinado a comparação do grupo de jovens delinquentes e não delinquentes, para este último, 108 jovens compuseram a amostra, sendo a maioria mulheres (56\%) e a média de idade é de 26.5 anos (d.p. $=0,45)$

Conhecido as características sociodemográficas e antes de atender aos objetivos pretendidos, foram realizadas análises estatísticas referente a qualidade da amostra coletada. Por tanto, de forma hierárquica, realizaram-se as seguintes avaliações:

1- Em relação aos dados omissos do estudo, eles não foram maiores do que o percentual exigido (> 5\%). Na concepção de Tabachnick e Fidell (2001), esta condição permite que, caso seja encontrado no banco de dados, o sujeito que não respondeu um item ou por ter havido duplicação, isto é, repetição de um mesmo número no espaço de resposta de um mesmo item, seja realizada a substituição da média ou moda dos dados da amostra;

2- No que se refere a multicolineariedade entre as variáveis, as correlações entre elas permaneceram dentro dos parâmetros definidos por Tabachnick e Fidell (2001) [r $\geq$ 0,90]; neste estudo tais correlações variaram de -0,11 a 0,63]. Assim sendo, não houve variáveis com um alto grau de correlação, o que permite que os modelos hipotéticos sejam gerados com baixo erro.

3- Foram verificadas a presença de outliers multivariados na amostra; esta condição foi realizada através do teste de normalidade de Kolmogorov-Smirnov (KS), destinado a análise de amostras superiores a 100 sujeitos, para a qual observou-se uma normalidade, seja para à amostra geral $(K S=0,06, p$-valor $<0,20)$, seja para à amostra em função do sexo (homem, $\mathrm{KS}=0,12$, $\mathrm{p}$-valor $<0,10$ e mulher, $\mathrm{KS}=0,08, \mathrm{p}$-valor $<$ $0,21)$

Também, foi verificado a diferença em assimetria; a partir dos histogramas com superposição da curva normal e seus índices, bem como, tendo uma orientação nos parâmetros definidos por Miles e Shevlin (2001) [isto é, os autores supracitados, afirmam que, mesmo tendo os dados da amostra não apresentado uma distribuição normal, sendo o número estatístico de assimetria menor que 1,0, haverá pouco problema, e se ele se apresentar entre 1,0 e 2,0, ainda assim, é considerado aceitável]. Apesar de sustentar essa avaliação nestas considerações estatísticas, ao avaliar os índices de assimetria das medidas. Todos os valores encontrados permaneceram dentro dos parâmetros aceitáveis (variando de -0,16 a 1,72); especificamente, variaram para a medida de conduta desviante foi, respectivamente (Curtose [Ku] e Assimetria [Sk]), $\mathrm{Ku}=-1,24$ e Sk=0,52, para crenças disfuncionais $\mathrm{Ku}=-0,32$ e $\mathrm{Sk}=0,33$.

Devido a quantidade de variáveis independentes e dependentes mensurarem as opiniões dos mesmos respondentes na presente tese, pretendeu avaliar a variância comum do método (common method variance), a fim de verificar se os dados poderiam representar algum problema nos resultados esperados, especialmente, quanto ao viés de respostas; para isso, empregou-se o 
teste de um fator de Harman, o qual, tem o objetivo de examinar a existência de algum viés comum do método (VCM) nos dados coletados, (cf. Podsakoff, MacKenzie, \& Podsakoff, 2003).

Considerando essa análise, observou-se que, no único fator com Auto- valor acima de 1,00, este, apresentou percentual explicativo menor do que $50 \%$ (22,33\%) da covariância nas variáveis; esta condição implica a inexistência do problema de variância comum do método, não identificando os vieses de respostas. Verificou-se também, a tendência de não resposta (isto é, existem algum grupo de sujeitos que não responderam, o qual, poderá prejudicar o resultado?).

Usando o procedimento de Armstrong e Overton (1977), através do qual se avaliou as diferenças entre os primeiros $(n 1=10)$ e dos últimos $(n 2=10)$ participantes da pesquisa, utilizando o teste de Levene para verificar a igualdade das variâncias e um teste-t na igualdade dos meios; observou-se que não houve resultado significativo a um nível de $5 \%$ entre os escores médios dos constructos (com $t \leq 1,96$ ), revelando com isso, a não existência de viés de não resposta, excluindo qualquer problema para as análises a serem realizadas.

Considerando que a condição da amostra não representa problemas para as análises, pois, revelou-se, a partir dos critérios estatísticos, que ela atende a normalidade, podendo realizar os cálculos paramétricos destinados a avaliação da qualidade da medida e da variância dos escores médios entre as variáveis; sendo assim, optou-se em avaliar o quanto as escalas administradas para a tese são validas quanto ao seu conteúdo teórico de avaliação.

Em uma primeira análise estatística, com base nos pressupostos da Teoria Clássica dos Testes (TCT), os quais, referem-se a necessidade de avaliar se os itens são capazes de discriminar as respostas das pessoas com magnitudes próximas, considerando os grupos com pontuações dos escores inferiores e superiores em relação ao construto medido (cf. Formiga, Fleury, Fandiño, \& Souza, 2016), verificou-se o poder discriminativo dos itens.

Com isso, gerou uma pontuação total para cada escala e em seguida, efetuou-se sua mediana; os respondentes que apresentaram pontuação abaixo da mediana foram classificados como sendo do grupo inferior, já aqueles com pontuações acima da mediana foram definidos como do grupo superior (cf. Formiga, Fleury, Fandiño, \& Souza, 2016).

Considerando-se cada item da referida medida, efetuou-se um teste t de Student para amostras independentes e compararam-se ambos os grupos observando a discriminação de cada item da escala quanto as pessoas com magnitudes próximas estatisticamente significativas, observando que tanto para a ECAD, quanto para $Q E C D$, o t de student foi $\geq 1,96$ e $p<0,001$.

Ainda, com base na TCT, avaliou-se a representatividade de conteúdo itens-fator (trata-se da verificação da relação entre os itens e o constructo, o qual, tem como base a representatividade comportamento-domínio, buscando verificar a relação teórica do teste e as situações especificadas nos itens quanto aos aspectos esperados neles) (Formiga, Fleury, Fandiño, \& Souza, 2016). A partir do cálculo da correlação de Pearson (r), verificou-se a relação dos itens da escala com a pontuação 
total da mesma, esperando que estejam acima de 0,50; observaram-se correlações positivas e significativas que variaram de 0,56 a 0,84.

Com objetivo de verificar maior garantia na qualidade do conteúdo da ECAD e da QECD, realizando o cálculo do coeficiente de variação de Pearson (CV). Na concepção de Oliveira (2007, p. 88), a dispersão útil para a comparação do grau de concentração em torno de uma média de series distintas, não deverá ultrapassar $10 \%$, da variação, pois, com uma baixa dispersão, é possível afirmar que existe qualidade constructo-conteúdo; desta maneira, todos os itens apresentaram o coeficiente abaixo do critério exigido.

Com isso, tanto a ECAD quanto a QECD, é possível afirmar que os respondentes foram capazes de representar cognitivamente o conteúdo e sentido dos itens relacionados aos construtos abordados pelos autores que elaboraram estas medidas (cf Formiga \& Gouveia, 2003; Rocha, Formiga, \& Lopes, 2016; Formiga, Duarte, Neves, Machado, \& Machado, 2015).

A partir da avaliação da análise de conteúdo verificar a confiabilidade das escalas. Tal condição, de acordo com Hair, Anderson, Tatham e Black (2008), pode-se avaliar através de um indicador psicométrico, chamado alfa de Cronbach, se a medida utilizada é consistente a mensuração do conceito do constructo que se pretende medir. A pretensão em utilizar esse indicador, mesmo que tenha observado, nos estudos dos autores supracitados alfas que garantiram a fidedignidade da medida é preciso destacar que a utilização deste indicador psicométrico, oferecem mais benefícios do que tautologia científica (cf. Rocha, Formiga, \& Lopes, 2013); isto é, quanto mais se conhece os escores dos alfas em termos temporais, contextuais e amostrais de uma medida, melhor a garantir na qualidade teórica e empírica abordada, contribuindo com isso, para o desenvolvimento do instrumento.

Sabe-se que tem utilizado tradicionalmente, o alpha de Cronbach $(\alpha)$ (devendo ser $\geq 0,70$, mas, também, valores até 0,60 são aceitáveis) para avaliar a consistência de um instrumento em determinado contexto amostral administrado (cf. Pasquali, 2011; Hair Jr et al., 2008; Hutz, Bandeira, \& Trentini, 2015). A partir do cálculo do alfa de Cronbach para as referidas escalas, os alfas estiveram acima de 0,70 para todas as medidas. Pode-se destacar também, a qualidade da variação dos alfas quando, no cálculo era sugerido a exclusão de algum item. Desta maneira, confirma-se a qualidade homogênea das medidas, salientando que elas são fidedignas para a mensuração do seu conjunto teórico-empírico (ver Tabela 1).

Tabela 1: Escores dos alfas de Cronbach $(\alpha)$ das escalas administradas na tese.

\begin{tabular}{ccccc}
\hline Construtos/ Variáveis & \multicolumn{3}{c}{ Alfas de Cronbach $(\alpha)$} \\
\cline { 2 - 5 } & Geral & Variação & \multicolumn{2}{c}{ Estatística } \\
\cline { 3 - 5 } & & Alfa item excluído & $\mathrm{F}$ & $\mathrm{p}$-valor < \\
\hline CAD & 0,98 & $0,96-0,97$ & 24,56 & 0,001
\end{tabular}

Rev. Psicol Saúde e Debate. Out., 2020:6(2): 184-212. 


\begin{tabular}{ccccc} 
CA & 0,96 & $0,95-0,97$ & 13,53 & 0,001 \\
CD & 0,96 & $0,94-0,96$ & 20,78 & 0,001 \\
CRENÇAS DISFUNCIONAIS & 0,87 & $0,85-0,90$ & 15,38 & 0,001 \\
\hline
\end{tabular}

Fonte: Elaborada pelos autores.

Além do indicador alfa oferecer uma maior garantia psicométrica para as referidas medidas, utilizou-se associado a ele, a correlação intraclasse (ICC); observaram-se que os alfas para as medidas utilizadas nesta tese foram os seguintes: ECAD apresentou um ICC = 0,96 $([95 \% \mathrm{IC}]=$ 0,74-0,83) e as Crenças Disfuncionais ICC = 0,87 ([95\%IC] = 0,83-0,90). Sendo assim, não apenas existiram escores alfas acima do que era esperado, bem como, todos eles foram significativos. Com isso, é preciso destacar uma particularidade: os escores observados no intervalo de confiança Intraclasse (ICC), encontraram-se próximos aos observados no alfa de Cronbach $(\alpha)$, garantindo a confiabilidade das medidas na amostra avaliada.

Considerando que os constructos utilizados nesta tese foram confiáveis tanto em sua relação item-fator, quanto em termos da definição dos seus construtos; procurou-se verificar um modelo preditivo, no qual as crenças disfuncionais seriam capazes de explicar as condutas desviantes, bem como, as suas respectivas dimensões (conduta antissocial e delitiva).

Ao considerar o poder preditivo em uma variáveis sobre a outra, faz-se referência ao cálculo da análise de regressão múltipla; este tipo de cálculo visa, a partir de seus indicadores psicométricos, prever uma relação funcional entre as variáveis dependentes sobre as independentes, ao invés da relação causa e efeito proposto pela correlação de Pearson (Formiga, 2007).

Conforme afirma Fávero (2015), o modelo de regressão múltipla tem por interesse fornecer informações acerca de fenômenos que são representados por variáveis métricas ou quantitativas, com finalidade principal de investigar as dependências entre variáveis explicativas e sua relação com uma variável dependente métrica (fenômeno em estudo).

Segundo Hair et al. (2008), a importância da utilização da regressão múltipla para o estudo preditivo entre as variáveis, provém de suas diversas informações concedidas que serão úteis para a interpretação dos fenômenos complexos. Para Kutner et al. (2004), a análise de regressão tem importância por fornecer dados estatísticos e informações de uma ou mais variáveis quantitativas a partir de suas interações dependentes, podendo obter resultado para possíveis previsões.

Essa técnica oferece ao pesquisador a capacidade de verificar a correlação de qualquer variável independente com a variável dependente. Se essas correlações entre as variáveis se apresentam alta $(\geq 0,90)$, significa que provavelmente ela seja muito dependente da outra. Nessas perspectivas, utiliza-se o coeficiente de determinação $\left(R^{2}\right)$, uma técnica estatística que mede a proporção da variância de variáveis dependentes que possa ser explicada pelas variáveis 
independentes. $O$ valor do coeficiente $R^{2}$ varia entre 0 e 1 , sinalizando o nível de inter-relação das variáveis: quanto mais próximo de 1, será maior nível de significância explicativa pelo modelo de regressão (Malhotra, 2012, Hair Jr et al., 2008, Fávero et al., 2009).

Partindo desses pressupostos, efetuou-se o cálculo de análise de regressão múltipla, com o método Enter. A escolha deste método se deve a originalidade da presente tese, na qual, estabeleceu-se hipoteticamente, a predição das crenças disfuncionais sobre as condutas desviantes; para facilitar a leitura dos resultados significativos nas tabelas, estes, foram destacados em negrito.

Considerando as condutas desviantes como uma pontuação geral, na tabela 2, é possível observar que a dimensão Desconfiança/Abuso, Defectividade/Incompetência e Dependência/Vergonha das crenças disfuncionais, foram capazes de apresentar escores significativos para explicar as condutas desviantes.

Foram observados também, os indicadores de multicolinariedade da predição: a partir do indicador VIF (definida em português, Inflação da Variância do Fator - IVF), com base no fator de tolerância entre as variáveis (o qual, deverá apresentar escores que não excedam um valor acima de 5), podendo implicar na baixa qualidade do modelo empírico estimado (Hair Jr et al., 2008; Marôco, 2010).

Ainda na Tabela 2, pode-se destacar que estes indicadores, para cada variável, se encontram no limite de estimação exigida, com todos significativos $(p<0,01)$, o que permite afirmar que os resultados não apresentam multicolinearidade, contribuindo para a estimação do modelo pretendido, de acordo com o que expõem os resultados. 
Tabela 2 - Regressão múltipla dos efeitos das variáveis dependentes (Crenças disfuncionais) que predizem a variável independente (condutas desviantes).

\begin{tabular}{|c|c|c|c|c|c|}
\hline \multirow{2}{*}{$\begin{array}{l}\text { Preditores } \\
\text { (Crenças disfuncionais) }\end{array}$} & \multicolumn{5}{|c|}{$\begin{array}{c}\text { Variável critério: } \\
\text { Condutas Desviantes }\end{array}$} \\
\hline & $B$ & $S E$ & Beta & $\begin{array}{c}\mathrm{t} \\
(>1,96)\end{array}$ & VIF \\
\hline Intercepto & 36,33 & 21,99 & +-- & $2,65^{*}$ & --- \\
\hline Privação Emocional & $-0,51$ & 1,31 & $-0,03$ & $-0,39$ & $1,55^{\star}$ \\
\hline Abandono & 3,39 & 1,08 & 0,23 & $3,11^{*}$ & $1,23^{*}$ \\
\hline Desconfiança/Abuso & 0,20 & 1,44 & 0,01 & 0,14 & $1,75^{\star}$ \\
\hline Isolamento & 0,87 & 1,43 & 0,06 & 0,60 & $2,15^{\star}$ \\
\hline Defectividade/Incompetência & 4,26 & 1,45 & 0,28 & $2,93^{*}$ & $2,13^{\star}$ \\
\hline Fracasso & 2,03 & 1,57 & 0,14 & 1,29 & $2,56^{\star}$ \\
\hline Dependência/Vergonha & 2,09 & 1,24 & 0,24 & $2,68^{*}$ & $1,65^{\star}$ \\
\hline Vulnerabilidade & 1,59 & 1,23 & 0,11 & 1,29 & $1,58^{*}$ \\
\hline Emaranhamento & $-0,01$ & 1,55 & $-0,01$ & $-0,01$ & $2,15^{\star}$ \\
\hline Subjugação & $-1,27$ & 1,04 & $-0,09$ & $-1,22$ & $1,32^{*}$ \\
\hline Auto sacrifício & $-3,45$ & 2,31 & 0,22 & $2,49^{*}$ & $1,42^{*}$ \\
\hline Coeficiente de Regressão & \multirow{3}{*}{\multicolumn{5}{|c|}{$\begin{array}{l}0,37 \\
R^{2} \text { ajustado }=0,18(18 \%) \\
F(11 / 206)=2,85, p<0,001\end{array}$}} \\
\hline Variância Explicada & & & & & \\
\hline Modelo & & & & & \\
\hline
\end{tabular}

A partir desses resultados, observou-se nota-se apenas algumas variáveis foram significativas na predição da conduta desviante; o fato é que esperava-se uma maior quantidade de variáveis que pudessem predizer as condutas desviantes como um todo, mas, no cálculo geral com à amostra total, na qual, concentrava-se tanto uma amostra de delinquentes quanto de não delinquentes, é possível que as amostras tenham influenciado nas variáveis preditoras.

No contexto teórico abordado, as crenças disfuncionais teriam um alto poder preditivo em pessoas que tangenciam as normas sociais e/ou delinquentes; justamente, porque tais sujeitos não foram capazes de desenvolver e alicerçar cognitiva e emocionalmente as suas frustrações, sentido e função do comportamento para as relações interpessoais (cf. Rocha, Formiga, \& Lopes, 2016).

Sendo assim, optou-se em gerar um modelo preditivo, separando as amostras; efetuou-se o mesmo cálculo de análise de regressão múltipla, também, com o método Enter, para o qual, observaram os seguintes resultados: para a amostra de delinquentes, as dimensões Abandono ( $\beta$ $=0,21)$, Isolamento $(\beta=0,21)$, Defectividade/abuso $(\beta=0,37)$, Fracasso $(\beta=0,31)$, Vulnerabilidade $(\beta=0,20)$ e Subjugação $(\beta=0,26)$ das crenças disfuncionais, revelaram betas $(\beta)$ que predisseram, positivamente, as condutas desviantes $\left(R=0,50, R^{2}{ }_{\text {Ajustado }}=0,25, F(11 / 136)=2,64, p<0,001\right)$; no que se refere à amostra de não delinquentes, observou-se que apenas os betas preditivos estiveram para as dimensões Abandono ( $\beta=-0,26)$, Desconfiança/Abuso, Fracasso $(\beta=-0,27)$, Fracasso $(\beta$ $=-0,25)$, Dependência/Vergonha $(\beta=-0,21)$ e Auto sacrifício $(\beta=-0,23)$ das crenças disfuncionais $\left(R=0,35, R^{2}\right.$ Ajustado $\left.=0,02, F(11 / 104)=2,27, p<0,05\right)$, os quais, explicaram negativos e significativos 
para a conduta desviante. O indicador VIF revelou que os indicadores preditivos, em cada variável, não apresentando multicolinearidade (todos $<5,00$ ), o que contribui para a estimação dos resultados do modelo.

Verificada a preditividade da conduta desviante (pontuação total), sabendo que este constructo se organiza em dois fatores (conduta antissocial e delitiva), optou-se por realizar também, uma análise preditiva associação as dimensões das crenças disfuncionais e das condutas antissociais, tanto para a amostra geral, quanto para amostra de delinquentes e não delinquentes; para facilitar a identificação dos resultados significativos, estes, foram destacados em negrito.

Em relação a conduta antissocial, o resultado para à amostra total, enquanto o fator Abandono $(\beta=0,31)$ prediz positivamente, por outro lado, 0 Fracasso $(\beta=-0,28)$, Dependência/Vergonha $(\beta=-0,29)$ e Auto sacrifício $(\beta=-0,21)$, explicou negativamente, tal conduta $\left(R=0,28, R^{2}{ }_{\text {Ajustado }}=0,03, F(11 / 206)=2,64, p<0,05\right)$. Com a amostra de delinquentes, observaram betas $(\beta)$ significativos, para Fracasso $(\beta=0,20)$, Dependência/Vergonha $(\beta=0,28)$ e Subjugação $(\beta=0,26)\left(R=0,33, R^{2}{ }_{\text {justado }}=0,03, F(11 / 206)=1,30, p<0,23\right)$, todos predizendo positivamente; já com a amostra de não delinquentes, o fator Desconfiança/Abuso $(\beta=-0,30)$, Fracasso $(\beta=-0,23)$, Dependência/Vergonha $(\beta=-0,22)$ e Auto sacrifício $(\beta=-0,26)$, predisseram negativamente, a conduta antissocial $\left(R=0,39, R^{2}{ }_{\text {Ajustado }}=0,05, F(11 / 206)=2,49, p<0,05\right)$. Nestes resultados, o VIF apresentou indicadores que comprovam em não apresentarem multicolinearidade, para o modelo pretendido.

No que diz respeito a preditividade da conduta delitiva, na qual, a partir de uma análise regressão referente a amostra total, revelou-se que os fatores Abandono $(\beta=0,25)$, Fracasso $(\beta=$ $-0,23)$, Vulnerabilidade $(\beta=0,24)$ e Auto sacrifício $(\beta=-0,26)$ das crenças disfuncionais, predisseram a conduta delitiva $\left(R=0,34, R^{2}{ }_{\text {Ajustado }}=0,07, F(11 / 206)=2,59, p<0,05\right)$. Com a amostra de delinquentes, a Defectividade/Incompetência $(\beta=0,20)$, Fracasso $(\beta=0,21)$, Dependência/Vergonha $(\beta=0,22)$, Subjugação $(\beta=0,24)$ e Auto sacrifício $(\beta=0,25)$, foram capazes de predizer a conduta delitiva $\left(R=0,45, R^{2}{ }_{\text {Ajustado }}=0,12, F(11 / 135)=2,56, p<0,01\right)$; já com a amostra de não delinquentes, o fator Desconfiança/Abuso $(\beta=-0,25)$, Isolamento $(\beta=-0,27)$, Dependência/Vergonha $(\beta=-0,28)$ e Vulnerabilidade $(\beta=-0,30)$, predisse negativamente a conduta delitiva $\left(R=0,35, R^{2}\right.$ Ajustado $\left.=0,01, F(11 / 108)=2,10, p<0,05\right)$. Nestes resultados, observou-se, também, que o VIF revelou a inexistência de multicolinearidade, destacando com isso, a segurança do modelo preditivo estabelecido; os resultados significativos foram destacados em negritos.

\section{DISCUSSÃO}


De forma geral, destaca-se que as escalas de medida das crenças disfuncionais e das condutas desviantes utilizadas no artigo, revelaram que elas são adequadas e fidedignas. Esta afirmação foi garantida na análise da discriminação dos itens, da representatividade de conteúdo, pois, além de ser significativa a diferença entre os escores nos extremos dos itens de cada escala, as suas correlações garantiram a força e direção do conteúdo relacionado ao item (este, foram > $0,50)$.

Salienta-se também, os percentuais do CV de Pearson (Coeficiente de Variação), revelando baixa dispersão do grau de concentração em torno das diferenças entre as médias, isto é, foram menor do que 10\%, garantindo uma boa qualidade na associação item-conteúdo de cada construto.

Diante dessas evidências empíricas, pode-se afirmar que as escalas avaliaram com eficácia, especificamente, a conduta desviante e as crenças disfuncionais, tornando-se uma ferramenta muito útil na avaliação do fenômeno da delinquência em jovens. Ao comparar os resultados observados neste estudo, aos achados nas pesquisas em diversos autores (cf. Formiga \& Gouveia, 2003; Formiga, Duarte, Neves, Machado,\& Machado, 2015; Formiga, Souza, Estevam,\& Omar, 2016; Rocha, Formiga,\& Lopes, 2013; Maia, Formiga, Tolentino, Lima,\& Sousa, 2018; Rocha, Formiga, \& Lopes, 2014), pode-se destacar que as medidas são invariantes. Considerando a consistência dos alfas, bem como, na avaliação do ICC (correlação intraclasse), além de todos estarem acima de 0,70 , os intervalos de confiança destes indicadores mantiveram o nível do escores de fidedignidade.

Ao avaliar o poder preditivo das crenças disfuncionais sobre as condutas desviantes; especialmente, no que diz respeito ao modelo preditivo em amostras de jovens delinquentes e não delinquentes, destaca-se que as crenças disfuncionais de Abandono, Defectividade/Incompetência, Dependência/Vergonha e Auto sacrifício, explicaram, positivamente, as condutas desviantes.

Tais resultados, merecem maior especificidade de compreensão, pois, com à amostra total, na qual, incluiu a amostra de delinquentes e não delinquentes, com a pontuação geral das condutas desviantes, é possível que tenha sofrido interferência dos escores nos critérios preditivos, provavelmente, a amostra de jovens delinquentes podem ter inflado o resultado, fazendo com que aumentasse os escores médios entre as variáveis e assim, divergindo da hipótese esperada.

Estas crenças, na concepção de Rocha, Formiga e Lopes (2013), podem condir os jovens a maior inserção no crime; o estudo desses autores com presidiários, confirmam que o sujeito ao fixar-se em crenças do tipo que foram observadas na análise preditiva, estarão mais predispostos ao crime, do que aqueles que têm a possibilidade de se reorganizar, cognitiva, social e afetivamente, fazendo com que, tais relações possam apresentar- se de forma inversa, isto é, provavelmente, expressariam uma menor conduta desviante.

Devido aos resultados estarem confusos, as amostras foram separadas ( $\mathrm{N} 1$ = delinquentes e N2 = não delinquentes), tendo observado achados mais lógicos e compreensíveis. Na amostra de Rev. Psicol Saúde e Debate. Out., 2020:6(2): 184-212. 
delinquentes, as crenças predisseram positivamente a conduta desviante (pontuação total), a conduta antissocial e a delitiva, por outro lado, com a amostra de não delinquentes, os resultados foram negativos.

Provavelmente, estes primeiros jovens (os delinquentes), tem menor capacidade cognitiva para assimilar e acomodar as crenças sobre si mesmo, quanto ao processo de reconhecimento de limite e dinâmica socializadora na administração parental frente a responsabilidade e exigência, conduzindo a um baixo nível de frustração (Formiga, 2012; Rocha, Formiga, \& Lopes, 2013; Nunes, Caridade, Oliveira, Costa, Carvalho, \& Guerra, 2015).

Ao considerar que crenças disfuncionais do tipo Abandono (referente a percepção de que as pessoas com quem poderia se relacionar são instáveis ou não são dignas de confiança), Defectividade/Incompetência (diz respeito a presença de sentimento de que é falho, mau, indesejado, inferior ou inválido em aspectos relevantes, não sendo digno de amor), Fracasso (relativo a crença de que fracassou ou irá fracassar de forma inevitável, ou de que é inadequado em relação aos demais (colegas de trabalho e desporto, etc.), no que se refere às conquistas pessoais), Vulnerabilidade (diz respeito ao medo exagerado de que um catástrofe, que está por vir, irá Ihe acometer, sem que possa impedir) e Subjugação (refere-se a submissão excessiva ao controle dos outros, por se sentir coagido e como forma de evitar a raiva, retaliação e o abandono) (cf. Callegaro \& Landeira-Fernandez, 2007; Rocha, Formiga, \& Lopes, 2013), ter explicado positivamente as condutas desviantes, bem como, a antissocial e delitiva, esta, tem uma relação teórica bem clara.

Considerando a reflexão acima, os participantes da pesquisa, provavelmente, teriam dificuldades com os esquemas vinculados ao seu sistema e funcionalidade cognitiva, prejudicando nos padrões de funcionamento que estão associados aos esquemas primários e que podem ser explicados, de forma mais consistente, a partir da referência ao esquema nuclear principal (Rocha, 2011).

De acordo com a concepção de Rocha, Formiga e Lopes (2013), na abordagem teórica defendida por Young (2003), o profissional que desenvolve e aplica tais perspectivas, apresenta aos sujeitos que o buscaram uma identificação destes esquemas cognitivos, a fim de que os participantes, procurem tornar conscientes das memórias, emoções, sensações corporais e cognições associadas aos mesmos, desenvolvendo com isso, o autoconhecimento, capaz de controlar suas reações, o que aumenta seu poder de escolha e deliberação consciente em relação a essas crenças.

Tal condição a partir desses resultados, revela que, ainda, não é possível uma dinâmica sociocognitiva para os jovens delituosos, pois, provavelmente, por não terem um apoio terapêutico, pouco se dispõem em 'abrir-se mental e socialmente" para uma nova forma de perceber a vida e 
interagir-se, capaz de avaliar os motivos e consequências das suas condutas sociais (Formiga, Aguiar, \& Omar, 2008).

Condição distinta foi observada nos resultados dos jovens não delinquentes, para os quais, os indicadores preditivos foram negativos; isto é, provavelmente, tais jovens podem ter maior disposição para uma reorganização cognitiva; mesmo que não tenha informação de que estes respondentes estejam em análise psicológica na área cognitivo-comportamental, perspectiva teórica desta tese, para os autores supracitados, o processo de socialização e controle social, poderá, inicialmente, contribuir para um melhor desenvolvimento e organização mental desses jovens.

Tal reflexão é reforçada no estudo de Formiga (2014), o qual descobriu que a associação afetiva com pais e professores não apenas inibem diretamente a conduta desviantes, mas, é capaz de gerar espaços de atividades de lazer, os quais, de forma mediacional, influenciam, no afastamento dos jovens nesse tipo de conduta.

Um outro resultado que chamou atenção, foi quanto a observação dos achados entre homens e mulheres em relação as condutas desviantes, nas quais, não houve diferença significativa. Tais resultados diferenciam-se dos estudos, com as mesmas variáveis, desenvolvidos por Formiga, Duarte, Neves, Machado e Machado (2015), Formiga, Souza, Estevam e Omar (2016) e Maia, Formiga, Tolentino, Lima e Sousa (2018), respectivamente, as mulheres foram mais desviantes, tendo nos dois últimos estudos, os homens apresentaram escores mais altos nas condutas desviantes.

Uma explicação coerente para os resultados relativos ao sexo e condutas desviantes, poderá relacionar-se ao contexto cultural, no qual, homens e mulheres poderão compreender de forma semelhante tais condutas, inclusive como um comportamento comum entre eles devido a fase do desenvolvimento, isto é, a adolescência, ser uma expressão de reivindicação e questionamentos entre os sexos (cf. Formiga \& Camino, 2001).

Por outro lado, os resultados que se esperavam, referentes aos jovens delinquentes e não delinquentes, corroborou praticamente essa hipótese, tendo os jovens delinquentes apresentado escores três vezes mais alto do que os não delinquentes. Esses achados, ao comparar com estudos separados, realizado por Maia, Formiga, Tolentino, Lima e Sousa (2018) com não delinquentes e Rocha, Formiga e Lopes (2013) com presidiários, é possível observar que estes últimos, apresentaram escores maiores, se aproximando a perspectiva explicativa neste estudo.

Em relação as crenças disfuncionais entre homens e mulheres, apenas no esquema de personalidade de Desconfiança/Abuso (referentes a expectativa de que os demais irão machucar, enganar, humilhar, abusar, mentir, manipular ou aproveitar-se de forma intencional ou como resultado de uma negligência injustificada), Isolamento (Sentimento de isolamento, de que é diferente dos demais ou de não pertencer a nenhum grupo) e Defectividade/Incompetência (diz 
respeito a presença de sentimento de que é falho, mau, indesejado, inferior ou inválido em aspectos relevantes, não sendo digno de amor), as mulheres apresentaram escores maiores.

Pode-se observar que tais esquemas, provavelmente, estarão associados a contextos culturais de valoração e qualificação da mulher, os quais, parece ser fomentado por uma luta constante delas em Angola (cf. Silva, 2011; Liberato, 2016). Assim, esse resultado é capaz de representar o quanto a mulher jovem (muito jovem) angolana pensa e sente em seu contexto social, mesmo com um avanço social e econômico permitindo que elas avancem socialmente, ainda assim, é preciso aderir aos papéis sexistas (Mesquita Filho, Eufrásio, \& Batista, 2011; Formiga, Gonçalves, \& Santos, 2018), os quais, poderão desenvolver uma espécie de dissonância sociocognitiva entre elas e as demandas sociais.

No que diz respeito aos esquemas de personalidade das crenças disfuncionais, os jovens delinquentes apresentaram os maiores escores, comparado aos não-delinquentes; especificamente, na Privação emocional (Expectativa de que o desejo de ter um grau satisfatório de apoio emocional não será satisfeito), Abandono (Percepção de que as pessoas com quem poderia se relacionar são instáveis ou não são dignas de confiança), Isolamento (Sentimento de isolamento, de que é diferente dos demais ou de não pertencer a nenhum grupo), Defectividade/Incompetência (Presença de sentimento de que é defectivo, falho, mau, indesejado, inferior ou inválido em aspectos relevantes, não sendo digno de amor), Fracasso (Crença de que fracassou ou irá fracassar de forma inevitável, ou de que é inadequado em relação aos demais (colegas de trabalho, e desporto, etc.), no que se refere às conquistas pessoais), Dependência/Vergonha (Crença de que é incapaz de cumprir as responsabilidades do cotidiano de modo competente, sem a ajuda dos demais) e Auto sacrifício (Foco excessivo no cumprimento das necessidades dos demais em situações do cotidiano, em detrimento e suas próprias gratificações) foram maiores para o grupo de delinquentes, esquemas estes, que estão direcionados nos domínios cognitivos destinados a falta de conexão com a realidade social, autonomia, empatia, etc., estes, são esquemas que favorecem uma boa relação interpessoal e preservação da harmonia do próprio sujeito (cf. Young, 2003; Rocha, Formiga, \& Lopes, 2013).

Por fim, em relação ao nível etário do desenvolvimento, é possível observar uma espécie de hierarquias desenvolvimentistas, considerando a distribuição das idades associada as fases da adolescência (início, intermediária, final e jovem adulto); percebe-se que os escores médios aumentam de acordo com as fases da adolescência, tendo a última fase (jovem adulto) apresentado escores maiores.

Esses resultados estão bem próximos dos observados por Formiga, Souza, Estevam e Omar (2016); pois, no estudo desses autores, os jovens mais velhos, também tiveram escores mais altos. Associados aos achados desse artigo, tais evidências direcionam para "a necessidade de que uma intervenção precoce poderia ser eficaz na redução de práticas delinquentes, já que a aplicação de 
sanções punitivas, quer na inibição de condutas delitivas, quer na prevenção da reincidência, não são muito eficientes" (p. 137).

\section{CONSIDERAÇÕES FINAIS}

De forma geral, espera-se que os objetivos principais tenham sidos atendidos; procurou-se apresentar e discutir os resultados da análise sobre um modelo preditivo da conduta desviante e suas dimensões (conduta antissocial e delitiva) em função das crenças disfuncionais. Ao verificarse à adequabilidade dos construtos teóricos abordados, não somente se confirmou a relação itemconteúdo das escalas, mas, também, que elas empiricamente estão proximas aos achados pelos autores supracitados em estudos com amostra em diferentes contextos sociais, econômicos e culturais.

Com isso, ao pretender mensurar a conduta desviante e as crenças disfuncionais para os jovens angolanos, sugere a necessidade da utilização destas medidas, as quais, devem associarse a cuidados metodológicos e teóricos na avaliação, já que são grupos distintos.

Os estudos sobre condutas desviantes tendo como preditividade uma perspectiva teórica personalística, não apenas revelaram complexidades, apesar da existência de diversos modelos teóricos que sugerem a influência de construtos personalísticos sobre as condutas desviantes; este artigo propôs considerar uma perspectiva mais cognitivista da personalidade.

Portanto, considerou o estudo das condutas desviantes não somente a especificidade de uma área da ciência psicológica, isto é, o engajamento da teoria da personalidade, mas, também, sua inserção num campo multidisciplinar podendo ser contemplado nas áreas afins desta ciência, bem como, podendo ser aplicado em uma perspectiva terapêutica in locus, capaz de contribuir para uma nova organização e funcionalidade cognitiva na orientação do comportamento interpessoal e social dos mais distintos jovens (seja delinquentes ou não).

Acredita-se que tais resultados, possam ser considerados úteis no emprego em estudo nas áreas da psicologia jurídica e criminal, bem como, psicologia do desenvolvimento, da educação e social. Apesar de observar que esses resultados tenham oferecido alguma direção de aplicabilidade do modelo teórico apresentado neste artigo, faz-se necessárias replicações e comparações em diferentes amostras e de instrumentos de medida em contextos sociais, econômicos, culturais diversos, de acordo com o sugerido por Formiga (2014).

Diante da configuração destes resultados, apesar dos limites metodológicos e conceptuais, inerentes a qualquer pesquisa científica; neste caso, refere-se ao acesso "concreto" no desenvolvido das abordagens teóricas (isto é, crenças disfuncionais sobre comportamentos 
antissociais) relativo aos resultados deste estudo, o qual, contribuiu para o entendimento do fenômeno, onde envolve os jovens em questão.

Com isso, sugere-se que a par destes achados, sejam realizados num futuro breve, pesquisas relacionadas á avaliação da complexidade de tais variáveis, quanto ao fenómeno da delinquência, envolvendo não apenas jovens, na categoria de alto risco, mastambém, aqueles que se encontram inseridosem institucionais sociais, como por ex: escolas, estrutura familiar e social.

\section{REFERÊNCIAS}

Agra, C., \& Matos, A. (1997). Droga/crime: Estudos interdisciplinares. Trajectórias desviantes. Lisboa, Portugal: Gabinete de Planeamento e de Coordenação do Combate à Droga.

Armstrong, J. S. \& Overton, T. S. (1977) Estimating nonresponse bias in mail surveys, Journal of Marketing Research, 14, 1977, 396-402.

Beck, A. e Freeman, A. (1993). Terapia cognitiva dos transtornos de personalidade.Tradução organizada por A.E. Fillman. Porto Alegre: Artes Médicas. (sem data da publicação original).

Beck, A. T., Butler, A. C., Brown, G. K., Dahlsgaard, K. K., Newman, C. F., \& Beck, J. S. (2001). Dysfunctional beliefs discriminate personality disorders. Behaviour Research and Therapy, 39(10), 1213-1225. https://doi.org/10.1016/S0005-7967(00)00099-1

Beck, A. T., Butler, A. C., Brown, G. K., Dahlsgaard, K. K., Newman, C. F., \& Beck, J. S. (2001). Dysfunctional beliefs discriminate personality disorders. Behaviour Research and Therapy, 39(10), 1213-1225.

Beck, A. T., Freeman, A., \& Davis, D. D. (2005). Terapia Cognitiva dos Transtornos de Personalidade ( $2^{\underline{a}}$ edição ed.). Porto Alegre: Artmed.

Beck, J. S. (1997). Terapia cognitiva: Teoria e prática (S. Costa, trad.). Porto Alegre, Brasil: Artmed.

Beck, J. S. (2013). Terapia cognitiva Comportamental, teoria e prática , Trad. Sandra Mallmann da Rosa, Porto Alegre: Artmed, 2013, 2ª Edição.

Born. M, (2005). Psicologia da Delinquência, Lisboa. Editora Climepsi.

Carvalho, M. J. L. (2005). Jovens, Espaços, Trajectórias e Delinquências. Sociologia, Problemas e Práticas, 49, 71-93.

Carvalho, P. (2008). Exclusão Social em Angola. O caso dos deficientes físicos de Luanda. Portugal: Editora Kilombelombe.

Carvalho, S. (2011). Antimanual de criminologia. Rio de Janeiro: Lumen Juris.

Cazassa, M. J. (2007). Mapeamento de esquemas cognitivos: validação da versão brasileira do Young Schema Questionnaire - Short Form. Dissertação de mestrado não-publicada, Pontifícia Universidade Católica do Rio Grande do Sul, Porto Alegre. 
Cazassa, M. J., \& Oliveira, M. S. (2008). Terapia focada em esquemas: Conceituação e pesquisas. Revista Psiquiatria Clínica, 35(5), 187-195.

Costa, M. R., \& Pimenta, C. A. M. (2006). A violência: natural ou sociocultural? São Paulo: Paulles. (Coleção Questões Fundamentais do Ser Humano).

Faul F., Erdfelder E., Buchner A., Lang A.-G. (2009). Statistical power analyses using G*Power 3.1: tests for correlation and regression analyses. Behavior Research Methods, 41, 1149-1160

Fávero, L. P. L. (2015). Análise de dados: Modelos de regressão com Excel®, Stata® e SPSS®. Rio de Janeiro: Elsevier.

Formiga, N. S. \& Camino, L. (2001). A Dimensão do Inventário de Papeis Sexuais (BSRI): A masculinidade e feminilidade em universitários. Estudos de Psicologia, 18, (2), 41-49

Formiga, N. S. \& Diniz, A. (2011). Estilo da orientação cultural e condutas desviantes: Testagem de um modelo teórico. Revista Pesquisa em Psicologia, 5(1), 2-11.

Formiga, N. S. (2014). Comparação fatorial e fidedignidade de uma medida sobre excesso de consumo de álcool em universitários brasileiros. Eureka: Revista de Investigación de Psicología, 11(1), 77-94

Formiga, N. S., \& Camino, L. (2001). A dimensão do inventário de papéis sexuais (BSRI): a masculinidade e feminilidade em universitários. Estudos de Psicologia (Campinas), 18(2), 4149. https://dx.doi.org/10.1590/S0103-166X2001000200004

Formiga, N. S., \& Gouveia, V. V. (2003). Adaptação e validação da escala de condutas anti-sociais e delitivas ao contexto brasileiro. Psico, 34, 367-388

Formiga, N. S., \& Gouveia, V. V.. (2005). Valores humanos e condutas anti-sociais e delitivas. Psicologia: teoria e prática, 7(2), 134-170. Recuperado em 01 de mar• o de 2019, de http://pepsic.bvsalud.org/scielo.php?script=sci arttext\&pid=S1516$36872005000200006 \& \operatorname{lng}=\mathrm{pt} \& \mathrm{t} \operatorname{lng}=\mathrm{pt}$.

Formiga, N. S., Aguiar, M., \& Omar, A. (2008). Busca de sensação e condutas anti-sociais e delitivas em jovens. Psicologia: Ciência e Profissão, 28(4), 668-681. https://dx.doi.org/10.1590/S1414$\underline{98932008000400002}$

Formiga, N. S., Melo, G., \& Leme, J. (2013). Pares sócio-normativos, orientação cultural, hábitos de lazer e condutas desviantes: verificação de um modelo teórico em jovens. Revista de Psicologia Universidade de Antioquia, 5, 7-26.

Formiga, N. S.; Goncalves, G. ; Santos, J. (2018). Sexismo ambivalente, los valores métricos y diferencias entre portugueses y brasileños personas. Eureka: revista científica de psicologia, $15(2), 207-224$.

Formiga, N., Duarte, V., Neves, S., Machado, M., \& Machado, F. (2015). Escala de Condutas Antissociais e Delitivas: Estrutura Fatorial da Versão Portuguesa. Psicologia: Reflexão e Crítica, 28(4), 718-727. https://dx.doi.org/10.1590/1678-7153.201528409

Formiga, N., Fleury, L. F. O., Fandiño, A. M., \& Souza, M. A., (2016). Evidência Empírica de uma medida da Anomia Organizacional em trabalhadores brasileiros. Revista de Psicologia, 18 (1), 43-59. 
Freeman, A. (1998). O desenvolvimento das conceituações de tratamento na terapia cognitiva. Em A. Freeman \& F. M. Dattilio (Orgs.), Compreendendo a terapia cognitiva (p. 29-42).Campinas: Editorial Psy.

Friedberg, R. D.; \& Mcclure, J. M. (2004). A prática clínica de terapia cognitiva com crianças e adolescentes. Porto Alegre: Artmed.

Greenberger, D., \& Padesky, C. A. (1994). A mente vencendo o humor. Porto Alegre: Artmed.

Hair Jr, J. F. et al. (2005). Análise Multivariada de Dados. 5. ed. Porto Alegre: Bookman.

Hutz, C. S., Bandeira, D. R., \& Trentini, C. M. (Eds.). (2015). Psicometria. Porto Alegre: Artmed.

Kutner, M. H. et al. (2004). Applied Linear. 5. ed. New York: McGraw-Hill/Irwin.

Maia, M. de F. de M., Formiga, N. S., Tolentino, T. M., Lima, C. A. G., \& Sousa, B. V. de O. (2018). Comprovação da estrutura fatorial da medida de condutas antissociais e delitivas em jovens. Perspectivas Em Psicologia, 22(2). https://doi.org/10.14393/PPv22n2a2018-10

Malhotra, N. K. (2011). Pesquisa de Marketing: foco na decisão. 3. ed. São Paulo: Pearson Prentice Hall.

Marôco, João. (2010). Analise de equações estruturais: fundamentos teóricos, software \& aplicações. ReportNumb ed. Pêro Pinheiro.

Matos, M. G., Simões, C., \& Gaspar, T. (2009). Violência entre pares no contexto escolar em Portugal, nos últimos 10 anos. Revista Interações, 5 (13), 1-28. https://doi.org/10.25755/int.399

Mesquita Filho, M., Eufrásio, C., \& Batista, M. A. (2011). Estereótipos de gênero e sexismo ambivalente em adolescentes masculinos de 12 a 16 anos. Saúde e Sociedade, 20(3), 554567. doi:10.1590/s0104-12902011000300003

Miles, J. N. V., \& Shevlin, M. E. (2001). Applying regression and correlation: A guide for students and researchers. London: Sage Publications.

Montagner, H. (2008). A árvore criança, uma nova abordagem do desenvolvimento da criança. Editora: Piaget.

Nardi, F. L., Hauck F. N., \& Dell'Aglio, D. D. (2016). Preditores do Comportamento Antissocial em Adolescentes. Psicologia: Teoria e Pesquisa, 32(1), 63-70. https://doi.org/10.1590/010237722016011651063070

Neves, S., Duarte, V., Barbosa, R. C., \& Formiga, N. (2015), Violências na contemporaneidade no Brasil e em Portugal. Maia, Edições ISMAI.

Pacheco, J. T. B. (2004). Construção de Comportamento Antissocial em Adolescentes Autores Inflacionais;Uma análise a partir das praticas educativas e dos estilos parentais. (Porto Alegre): Tese de Doutoramento apresentada a Universidade Federal do Rio Grande do Sul.

Padesky, C. A. (1994). Schema change processes in cognitive therapy. Clinical Psychology and Psychotherapy, 1, 267-278. DOI: http://dx.doi.org/10.1002/cpp.5640010502 
Pasquali, L. (2011). Psicometria: teoria dos testes na psicologia e na educação. 4 ed. Petrópolis/RJ: Vozes.

Paulino, M. \& Almeida, F. (2014). Psicologia, Justiça e Ciências Forenses - Perspetivas Atuais. Lisboa: Pactor.

Pimenta, M. E. (2012).Quem Produz Delinquência,Modelos de Delinquência,(3a ed.). Lisboa: Volume II, Edição Calçada da Letras

Podsakoff PM, MacKenzie SB \& Podsakoff NP. Common method biases in behavioral research: a critical review of the literature and recommended remedies. J Appl Psychol [Internet]. 2003 [cited 2018 Ago 02]; $88 \quad$ (5): $079-903$. Available from: http://www.jwalkonline.org/docs/Grad\%20Classes/Survey/articles/required/Podsakoff\%2 0-\%20common\%20method\%20biases.pdf. DOI:10.1037/0021-9010.88.5.879

Redondo, S., \& Andrés Pueyo, A. (2007). Psicología de la delincuencia.Papeles del Psicólogo, 28 (3), p.7

Rocha, M. C. O. (2011). Estudo das Condutas Antissociais e Delitivas e Esquemas de Personalidade numa amostra de presidiários. Dissertação de mestrado. Universidade Federal de Uberlândia, Uberlândia-MG

Rocha, M. C. O., Formiga, N. S., \& Lopes, E. J. (2013). Una medida de la conducta desviada: La verificación empírica de estrutura fatorial de reclusos em Brasil. Eureka - Revista de investigação científica em psicologia, 10(2), 164-178.

Samohl, R. W. (2009). Controle Estatistico da qualidade. Rio de Janeiro: Elsevier.

Seisdedos, N. (1988). Cuestionario A-D de conductas antisociales - delictivas. Madri: TEA.

Silva, E. A. (2011). Tradição e identidade de género em Angola: ser mulher no mundo rural". Revista Angolana de Sociologia, 8, 21-34.

Simas, T. K. (2012). Profiling Criminal. Introdução a Análise Comportamental no Contexto Investigativo. Letras e Conceitos, Lda. Portugal

Simões, M. C. (2007). Comportamentos de Risco na Adolescência. Coimbra: Fundação Calouste Gulbenkian.

Tabachnick, B.G. \& Fidell L.S. (2001). Using multivariate statistics. Needham Heights: Allyn \& Bacon.

Valente, M. I. (2001) A Situação da Mulher em Angola, 2001. Disponível em: Disponível em: http://ieham.org/html/docs/A Situacao Mulher em Angola.pdf .

Van de Vijver, F., \& Leung, K. (1997). Methods and data analysis for cross-cultural research. Thousand Oaks: Sage Publications.

Vasconcelos, T. C., Gouveia, V. V., Pimentel, C. E., \& Pessoa, V. S. (2008). Condutas desviantes e traços de personalidade: Testagem de um modelo causal. Estudos de psicologia (Campinas), 25(1), 55-65.

Rev. Psicol Saúde e Debate. Out., 2020:6(2): 184-212. 
Vasconcelos, T. C., Gouveia, V. V., Pimentel, C. E., \& Pessoa, V. S. (2008). Condutas desviantes e traços de personalidade: testagem de um modelo causal. Estudos de Psicologia (Campinas), 25(1), 55-65. https://dx.doi.org/10.1590/S0103-166X2008000100006

Vera, J. Á., Bautista, G., Ramírez, M., \& Yáñez, A. I. (2012). Relación entre anomia social, alienación y conducta antisocial en jóvenes infractores mexicanos. Revista Latinoamericana de Ciencias Sociales, Niñez y Juventud, 10 (2), 943-955.

White, W. F. (1943/2005). Sociedade de Esquina: A estrutura social de uma área urbana pobre e degradada. Rio de Janeiro: Jorge Zahar Editor.

Young, J. E (2003). Terapia Cognitiva para transtornos da personalidade: uma abordagem focada em esquemas. (3를 edição) (M.A.V. Veronese, Trad.). Porto Alegre: Artmed.

Young, J., Klosko, J., \& Weishaar, M. (2008). Terapia do esquema: Guia de técnicas Cognitivocomportamentais inovadoras. Porto Alegre: Artmed.

Zappe, J. G., \& Dias, A. C. G. (2010). Delinquência juvenil na produção científica nacional: distâncias entre achados científicos e intervenções concretas. Barbaroi, (33), 82-103. Recuperado em 15 de julho de 2020, de http://pepsic.bvsalud.org/scielo.php?script=sci arttext\&pid=S0104-

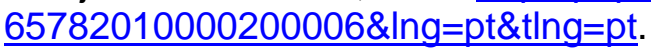

